\title{
Analisis Pengaruh Karakteristik Bank, Faktor Makroekonomi terhadap Pembiayaan Sektor UMKM pada Perbankan Syariah di Indonesia
}

\author{
Lutfi Bangun Lestari, ${ }^{1}$ Akhsyim Afandi ${ }^{2}$ \\ Universitas Islam Indonesia Yogyakarta \\ Email:lutfi.bngun1lestari@gmail.com, ${ }^{1}$ akhsyim@uii.ac.id ${ }^{2}$
}

Abstract

: MSMEs have an important role in national economic development, but the financing of the MSME sector always fluctuates from year to year and tends to decline. This study aims to analyze the effect of bank characteristics and macroeconomic factors on the financing of the MSME sector in Islamic banking in Indonesia. This study uses time series data which is monthly data on aggregate financial statements of Islamic Commercial Banks and Sharia Business Units in Indonesia. The analysis method used in this research is Autoregressive Distributed Lag (ARDL). The results showed that the variables that affect the financing of the BUS MSME sector in the short term are ROA and BI_Rate. Whereas in the long term, the variables that affect the financing of the BUS MSME sector are the bank office network and inflation. While DPK, NPF, exchange rates, ERP both in the short term and long term have no effect on the financing of the BUS MSME sector. Then the variables that affect UUS MSME sector financing in the short term are the bank office network, ROA and BI_Rate. Whereas in the long term, the variable that affects UUS MSME sector financing is the bank office network. Meanwhile, DPK, NPF, exchange rate, ERP both in the short and long term had no effect on the financing of the UUS MSME sector.

Keywords : MSME Financing; Bank Characteristics; Macroeconomic

Abstrak : UMKM mempunyai peranan penting bagi pembangunan ekonomi nasional, namun pembiyaan sektor UMKM pada perbankan syariah selalu mengalami fluktuasi dari tahun ke tahun dan cenderung mengalami penurunan. Penelitian ini bertujuan untuk menganalisis pengaruh karakteristik bank dan faktor makroekonomi terhadap pembiayaan sektor UMKM pada perbankan syariah di Indonesia. Penelitian ini menggunakan data time series yang merupakan data bulanan laporan keuangan agregat Bank Umum Syariah dan Unit Usaha Syariah serta yang ada di Indonesia. Metode analaisis yang digunakan dalam penelitian ini adalah Autoregressive Distributed Lag (ARDL). Hasil penelitian menunjukkan bahwa yang berpengaruh terhadap pembiayaan sektor UMKM BUS dalam jangka pendek adalah ROA dan BI_Rate. Sedangkan dalam jangka panjang variabel yang berpengaruh terhadap pembiayaan sektor UMKM BUS adalah jaringan kantor bank, dan inflasi. Sementara DPK, NPF, nilai tukar, ERP baik dalam jangka pendek maupun jangka panjang tidak berpengaruh terhadap pembiayaan sektor UMKM BUS. Kemudian yang berpengaruh terhadap pembiayaan sektor UMKM UUS dalam jangka pendek adalah jaringan kantor bank, ROA dan BI_Rate. Sedangkan dalam jangka panjang yang berpengaruh terhadap pembiayaan sektor UMKM UUS adalah jaringan kantor bank. DPK, NPF, nilai tukar, ERP baik dalam jangka pendek maupun jangka panjang tidak berpengaruh terhadap pembiayaan sektor UMKM UUS.

Kata Kunci : : Pembiayaan UMKM; Karakteristik Bank; Makroekonomi

\section{A. Pendahuluan}

UMKM merupakan sumber kehidupan ekonomi dari sebagian besar rakyat Indonesia, yang tersebar di seluruh daerah, kota, dan desa. Pertumbuhan Usaha Mikro, Kecil, dan Menengah (UMKM) mengalami pertumbuhan pada tahun $2018^{1}$. Kontribusi UMKM dalam penciptaan (PDB) pada pada akhir 2018 sebesar Rp 8,573 triliun atau sebesar 61,07\%. UMKM. Jumlah tenaga kerja sebanyak 116.978 .631 orang atau mencapai $97 \%$ dari total tenaga kerja Indonesia (UMKM dan Unit Besar). Jumlah UMKM di Indonesia sebanyak 64.194.057 unit atau 99,99\% dari total unit usaha di Indonesia.

\footnotetext{
${ }^{1}$ Trimulato; Ismawati; Amiruddin K; dan Nuraeni, 'Penguatan Peran Ekomomi Islam Melalui Optimalisasi Pembiayaan Pada Sektor Rill UMKM', Jurnal Ekonomi Syariah, 5.September (2020), 87-98.
} 
Pemerintah melihat UMKM juga sebagai salah satu kanal untuk mewujudkan pertumbuhan ekonomi inklusif artinya manfaat dari pertumbuan ekonomi dapat dirasakan oleh seluruh lapisan masyarakat, pertumbuhan ekonomi berkelanjutan yang lebih memperhatikan pemerataan akses dan kesempatan kepada semua lapisan masyarakat, serta menitikberatkan kepada penyerapan tenaga kerja produktif dari pada redistribusi pendapatan (BLT) untuk orang miskin. Pertumbuhan ekonomi Indonesia masih relatif stabil, pada tahun 2018 di kisaran $5,17 \%$ namun masih ada beberapa isu berkaitan dengan kualitas pertumbuhan diantaranya adalah ketimpangan pendapatan, kemiskinan, dan pengangguran yang secara tren terus turun tetapi nilainya masih besar, hal ini juga menjadi alasan pentingnya pengembangan UMKM untuk membantu pembangunan perekonomian di Indonesia.

Beberapa penelitian yang berkaitan dengan faktor-faktor yang mempengaruhi pembiayaan perbankan syariah menunjukkan hasil yang berbeda-beda. Jaringan Kantor Bank (JKB), Dana Pihak Ketiga (DPK), Return On Asset (ROA), Non Performing Financing (NPF), equivalent rate pembiayaan (ERP) merupakan variabel yang menggambarkan karakteristik perbankan yang mempengaruhi pembiayaan pada perbankan syariah. Penelitian yang dilakukan oleh Ali hasilnya menunjukkan bahwa Jaringan Kantor Bank (BUS) berpengaruh positif signifikan terhadap pembiayaan bagi hasil pada Bank Umum Syariah ${ }^{2}$. Hasil penelitian oleh Irawan menunjukkan bahwa DPK berpengaruh positif terhadap pembiayaan murabahah pada Bank Syariah $^{3}$. Sedangkan penelitian Beik \& Aprianti menunjukkan hasil bahwa DPK berpengaruh negatif dan signifikan terhadap pembiayaan bank syariah. ${ }^{4}$ Susilowati \& Nawangsasi menunjukkan hasil bahwa DPK berpengaruh signifikan terhadap pembiayaan bank umum syariah $^{5}$. Hasil penelitian Ningsih, bahwa ROA berpengaruh positif terhadap pembiayaan mudharabah pada bank umum syariah di Indonesia ${ }^{6}$. Sedangkan hasil penelitian Umiyati \& Ana menunjukkan bahwa ROA tidak berpengaruh terhadap pembiayaan bank umum syariah devisa $^{7}$. Penelitian yang berkaitan dengan NPF yang dilakukan oleh Warto \& Budhijana memiliki hasil yang menunjukkan bahwa NPF berpengaruh positif dan tidak signifikan terhadap pembiaayaan Bank Syariah ${ }^{8}$. Sedangkan penelitian yang dilakukan oleh Nurochman menunjukkan hasil bahwa NPF tidak berpengaruh signifikan terhadap pembiayaan mudharabah bank umum syariah Indonesia' 9 Penelitian oleh Ryad \& Yuliawati menunjukkan bahwa NPF tidak berpengaruh terhadap pembiayaan. Jaya dkk, menunjukkan hasil penelitiannya bahwa ERP pembiayaan berpengaruh negatif signifikan terhadap pembiayaan

\footnotetext{
${ }^{2}$ Mustofa, Ali, 'Analisis Pengaruh Jumlah Kantor Bank Umum Syariah (JKBUS), Sertifikat Bank Indonesia Syariah (SBIS), dan Dana Pihak Ketiga (DPK) Terhadap Pembiayaan Bagi Hasil Pada Bank Umum Syariah di Indonesia Periode 2015 - 2018', April, 2019.

${ }^{3}$ Irawan, Oki Khalil Jafril, dan Riawan Amin, 'Dana Pihak Ketiga, Rasio Kecukupan Modal, Pembiyaan Bermasalah, Dan Tingkat Pengembalian Investasi Pada Pembiayaan UMKM', Liquidity, 5.2 (2018), 127-33.

${ }^{4}$ Beik, Irfan Syauqi Beik dan Winda Nur Aprianti, 'Analisis Faktor-Faktor Yang Memengaruhi Pembiayaan Bank Syariah Untuk Sektor Pertanian Di Indonesia’, Jurnal Agro Ekonomi, 31.1 (2016), 19.

${ }^{5}$ Susilowati, Eko Meiningsih dan Endah Nawangsari 'Pengaruh Kinerja Keuangan Terhadap Penyaluran Pembiayaan Pada Bank Umum Syariah di Indonesia : Periode 2013-2015. Jurnal Ekonomi Dan Perbankan, 3.1 (2018), 10-18.

${ }^{6}$ Fitriani, Ningsih Devi, 'Analisis Faktor Yang Mempengaruhi Pembiayaan Mudharabah Pada Bank Umum Syariah Di Indonesia Periode 2013-2016', Jurnal Ilmiah Riset Akuntansi 6, 2017, 151.

${ }^{7}$ Umiyati dan Leni Tantri Ana, 'Faktor-Faktor yang Mempengaruhi Pembiayaan Pada Bank Umum Jurnal Ekonomi Dan Perbankan Syariah', November, 2018.

${ }^{8}$ Warto dan R Bambang Budhijana, 'Faktor - Faktor Yang Mempengaruhi Penyaluran Pembiayaan Perbankan Syariah Indonesia Periode 2009 - 2019', Al Maal: Journal of Islamic Economics and Banking, 1.1 (2019), 1-17.

${ }^{9}$ Nurochman, Rachmiawati Indah, 'Faktor Yang Mempengaruhi Pembiayaan Mudharabah Pada Bank Umum Syariah Di Indonesia', Accounting Analysis Journal, 2 (2019).
} 
perbankan syariah ${ }^{10}$. Sedangkan penelitian Yuningsih menunjukkan hasil yang berbeda dimana ERP pembiayaan berpengaruh terhadap pembiayaan perbankan syariah ${ }^{11}$. Adapun beberapa variabel faktor makroekonomi yang mempengaruhi pembiayaan perbankan syariah antara lain inflasi, nilai tukar dan tingkat suku bunga. Hasil penelitian oleh Astuti menunjukkan bahwa inflasi tidak berpengaruh secara signifikan terhadap alokasi pembiayaan pada bank syariah ${ }^{12}$. Adapun hasil penelitiannya tersebut berbeda dengan penelitian yang dilakukan oleh Dwijaya \& Wahyudi menunjukkan bahwa inflasi berpengaruh positif terhadap pembiayaan bank syariah ${ }^{13}$. Selanjutnya hasil penelitian yang berkaitan dengan nilai tukar yang dilakukan oleh Masudah yakni nilai tukar berpengaruh positif terhadap volume pembiayaan bank syariah ${ }^{14}$. Sedangkan hasil penelitian Kurniawan dan Sudrajat nilai tukar berpengaruh negatif terhadap pembiayaan UMKM bank umum syariah ${ }^{15}$. Penelitian oleh Wahiddudin menunjukkan hasil penelitiannya bahwa tingkat suku bunga berpengaruh negatif signifikan terhadap pembiayaan perbankan syariah ${ }^{16}$. Ardiasyah, dkk hasil penelitiannya menunjukkan bahwa tingkat suku bunga berpengaruh signifikan terhadap pembiayaan bank syariah ${ }^{17}$.

Hal ini menunjukkan adanya riset gap, sehingga memunculkan peluang bagi penulis untuk melakukan penelitian kembali dengan objek, metode serta waktu penelitian yang berbeda. Pada penelitian ini objek penelitiannya adalah pembiayaan sektor UMKM perbankan syariah. Dimana pembiayaan sektor UMKM pada BUS, dan pembiayaan sektor UMKM pada UUS sebagai variabel dependen. Kemudian untuk JKB, DPK, ROA, NPF, ERP, inflasi, nilai tukar, tingkat suku bunga sebagai variabel independen. Dengan demikian tujuan dari penelitian ini adalah untuk menganalisis pengaruh JKB, DPK, ROA, NPF, ERP, inflasi, nilai tukar, tingkat suku bunga terhadap pembiayaan sektor UMKM pada perbankan syariah di Indonesia.

\section{B. Metode Penelitian}

Penelitian menjelaskan hubungan kausalitas antara variabel dependen dan independen dengan pengujian hipotesis. Penelitian ini menggunakan pendekatan kuantitatif. Data yang digunakan dalam penelitian ini adalah data sekunder yang bersifat time series. Data time series merupakan data bulanan yang berasal dari publikasi Statistik Perbankan syariah dari OJK, Bank Indonesia, Badan Pusat Statistik periode Oktober 2014 sampai April 2020. Teknik pengumpulan data yang digunakan adalah studi kepustakaan dengan cara dokumentasi, yaitu

10 Jaya Yozar Putra, Rindayati Wiwiek, Ali Khalifah Muhammad, 'Analisis Faktor-Faktor Penentu Pembiayaan Perbankan Syariah Pada Sektor Pengangkutan Dan Komunikasi Di Indonesia', Al-Muzara'ah, 3.1 (2016), 62-75.

${ }^{11}$ Yuningsih, Ayu, 'Analisis Pembiayaan Sektor Jasa Dunia Usaha Pada Perbankan Syariah Di Indonesia', Al-Intaj,6.1 2020.

12 Astuti, Agnes Dwi 'Pengaruh Jumlah Dana Pihak Ketiga (DPK), Inflasi, BI Rate dan Financing To Deposit Ratio (FDR) Terhadap Alokasi Pembiayaan UMKM Pada Bank Umum Syariah’, 2017.

${ }^{13}$ Dwijaya, Putra Agung dan Sugeng Wahyudi, 'Analisis Pengaruh Variabel Makro Ekonomi, Dengan Demografi Dan Efek Krisis Keuangan Global Sebagai Variabel Kontrol Terhadap Pembiayaan Bank Syariah Di Indonesia (Studi Pada Bank Syariah Devisa Di Indonesia Periode 2007-2016)', Diponegoro Journal of Management, 7 (2018).

${ }^{14}$ Masudah, 'Determinan Volume Pembiayaan Bank Umum Syariah Indonesia', Ikonomika, 2.1 (2017), 53-62.

${ }^{15}$ Bambang Kurniawan dan Alpi M Sudrajat, 'Pengaruh PDRB Dan Nilai Tukar Terhadap Pembiayaan UMKM Pada Bank Umum Syariah di Provinsi Jambi Periode 2010-2017', Jurnal IJIEB, 1.1 (2017), 71-82.

${ }^{16}$ Wahiddudin, Muhammad 'Pengaruh Inflasi, Non Performing Finacing (Npf) dan Bi Rate Terhadap Pembiayaan Usaha Mikro Kecil dan Menengah (Umkm) Pada Bank Umum Syariah 2012-2017', Al Amwal, 1.1 (2018), 76-89.

${ }^{17}$ Ardiansyah, Hadira Thumaninah Jibril, David Kaluge, dan Kasnaeny Karim 'Permintaan Pembiayaan Murabahah Berdasarkan Tingkat Inflasi Dan Suku Bunga BI Rate Pada Bank Syariah Di Indonesia', Jurnal Bisnis Dan Manajemen, 13.1 (2019), 10-18. 
pengumpulan data sekunder dari buku-buku, jurnal-jurnal, informasi dari berbagai pihak, dan mengolah data yang berkaitan dengan penelitian. Populasi pada penelitian ini terdiri dari seluruh Bank Umum Syariah, dan Unit Usaha Syariah di Indonesia yang terdaftar di Otoritas Jasa Keuangan. Variabel dependen dari penelitian ini adalah pembiayaan sektor UMKM pada BUS, dan pembiayaan sektor UMKM pada UUS. Kemudian variabel independennya meliputi JKB, DPK, ROA, NPF, ERP, inflasi, nilai tukar, tingkat suku bunga. Analisis data dalam penelitian ini menggunakan metode Autoregressive Distributed Lag (ARDL). Adapun model analisis data yang digunakan adalah sebagai berikut:
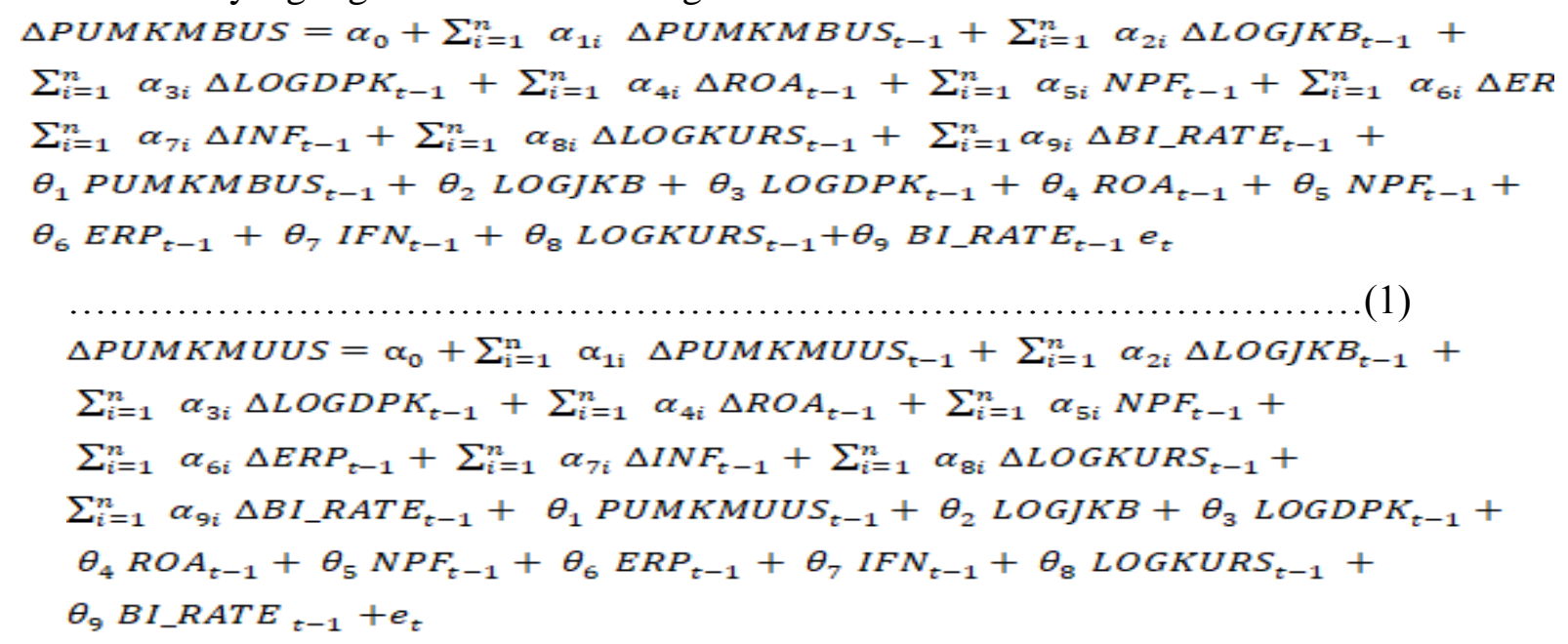

Pada model ARDL untuk melihat hubungan jangka panjang antara variabel dalam model maka dilakukan uji bound testing cointegration yang dikembangkan oleh Pesaran, Shin and Smith dengan cara mengestimasi persamaan umum ARDL yang menggunakan semua variabel independenya secara bergantian. Uji kointegrasi bound testing ini berdasarkan uji Statistik F. Adapun hipotesis nol (H0) dan hipotesis alternatif (Ha) dari persamaan 1 dan 2 di atas dapat ditulis sebagai berikut.

$$
\begin{aligned}
& H_{0}: \theta_{1}=\theta_{2}=\theta_{3}=\theta_{4}=\theta_{5}=\theta_{6}=\theta_{7}=\theta_{8}=0 \ldots \\
& H_{a} ; \theta_{1} \neq \theta_{2} \neq \theta_{3} \neq \theta_{4} \neq \theta_{5} \neq \theta_{6} \neq \theta_{7} \neq \theta_{8} \neq 0 \ldots
\end{aligned}
$$

Nilai F-Statistik hasil perhitungan akan dibandingkan dengan nilai-nilai kritis yang ditampilkan tabel. Nilai kritis batas bawah (lower bound critical value) mengasumsikan bahwa variabel-variabel penjelas kointegrasi dalam ordo nol atau I (0). Sementara nilai kritis teratas (upper bound critical value) mengasumsikan bahwa variabel-variabel penjelas terintegrasi dalam ordo satu atau I (1).

Dalam model ARDL ini, diuji pula model penyesuaian untuk melakukan koreksi bagi ketidakseimbangan jangka pendek dengan menggunakan model koreksi kesalahan. Adapaun model koreksi kesalahan dari persamaan ARDL sebelumnya $(1,2,3)$ adalah sebagai berikut

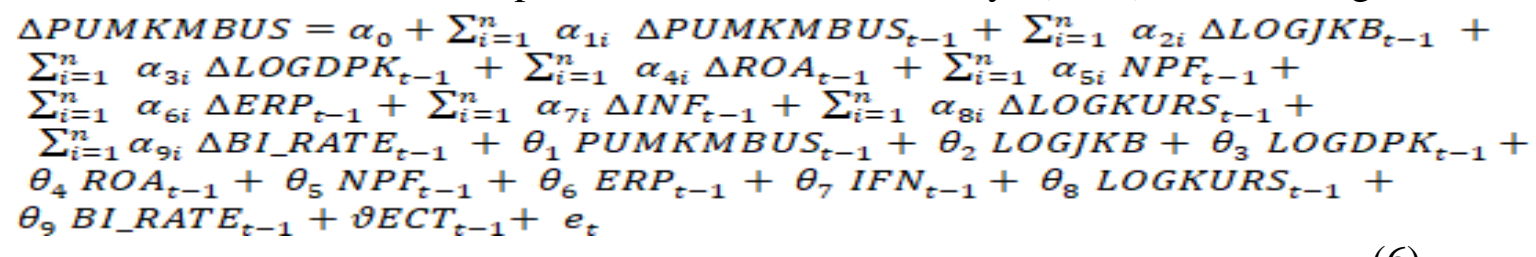




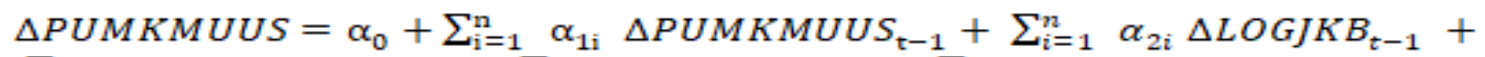
$\sum_{i=1}^{n} \alpha_{3 i} \triangle L O G D P K_{t-1}+\sum_{i=1}^{n} \alpha_{4 i} \triangle R O A_{t-1}+\sum_{i=1}^{n} \alpha_{5 i} N P F_{t-1}+$ $\sum_{i=1}^{n} \alpha_{6 i} \Delta E R P_{t-1}+\sum_{i=1}^{n} \alpha_{7 i} \Delta I N F_{t-1}+\sum_{i=1}^{n} \alpha_{8 i} \Delta$ LOGKURS ${ }_{t-1}+$ $\sum_{i=1}^{n} \alpha_{9 i} \triangle B I_{-} R A T E_{t-1}+\theta_{1}$ PUMKMUUS $S_{t-1}+\theta_{2}$ LOGJKB $+\theta_{3}$ LOGDPK $_{t-1}+$ $\theta_{4} R O A_{t-1}+\theta_{5} N P F_{t-1}+\theta_{6} E_{t} P_{t-1}+\theta_{7}$ IFN $_{t-1}+\theta_{8}$ LOGKURS $_{t-1}+$ $\theta_{9} B I_{-} R A T E_{t-1}+\vartheta E C T_{t-1}+e_{t}$

Dimana $\vartheta E C T_{t-1}$ : variabel koreksi kesalahan yaitu kesalahan (residual) periode sebelumnya.

\section{Hasil dan Pembahasan}

\section{Analisi Statistik Deskriptif}

Pada penelitian ini menggunakan data bulanan dari publikasi Statistik Perbankan syariah dari OJK, Bank Indonesia, Badan Pusat Statistik periode Oktober 2014 sampai April 2020. Sehingga total jumlah observasi adalah 67 observasi.

Tabel 1. Hasil Analisi Statistik Deskriptif

\begin{tabular}{|l|l|l|c|r|c|r|r|r|r|}
\hline & $\begin{array}{l}\text { P } \\
\text { UMKM } \\
\text { BUS }\end{array}$ & $\begin{array}{l}\text { P } \\
\text { UMKM } \\
\text { UUS }\end{array}$ & $\begin{array}{c}\text { LOG } \\
\text { JKB } \\
\text { BUS }\end{array}$ & $\begin{array}{c}\text { LOG } \\
\text { JKB } \\
\text { UUS }\end{array}$ & $\begin{array}{c}\text { LOG } \\
\text { DPK } \\
\text { BUS }\end{array}$ & $\begin{array}{c}\text { LOG } \\
\text { DPK } \\
\text { UUS }\end{array}$ & $\begin{array}{c}\text { ROA } \\
\text { BUS }\end{array}$ & $\begin{array}{c}\text { ROA } \\
\text { UUS }\end{array}$ & $\begin{array}{c}\text { NPF } \\
\text { UMM } \\
\text { BUS }\end{array}$ \\
\hline Mean & 26.2216 & 14.18029 & 7.558585 & 5.832267 & 12.27841 & 11.28426 & 1.01791 & 2.22119 & 6.53711 \\
\hline Maximum & 40.06139 & 20.19283 & 7.679251 & 5.963579 & 12.58132 & 11.80043 & 1.88 & 2.82 & 9.70645 \\
\hline Minimum & 22.44014 & 8.896108 & 7.427144 & 5.652489 & 12.00038 & 10.69267 & 0.16 & 1.68 & 4.16594 \\
\hline Observations & 67 & 67 & 67 & 67 & 67 & 67 & 67 & 67 & 67 \\
\hline
\end{tabular}

\begin{tabular}{|l|r|r|r|r|r|r|r|r|r|}
\hline & $\begin{array}{c}\text { NPF } \\
\text { UMKM } \\
\text { BUS }\end{array}$ & $\begin{array}{c}\text { NPF } \\
\text { UMKM } \\
\text { UUS }\end{array}$ & $\begin{array}{c}\text { ERP } \\
\text { MUDH } \\
\text { ABUS }\end{array}$ & $\begin{array}{c}\text { ERP } \\
\text { MUSY } \\
\text { BUS }\end{array}$ & $\begin{array}{c}\text { ERP } \\
\text { MUDH } \\
\text { AUUS }\end{array}$ & $\begin{array}{c}\text { ERP } \\
\text { MUSY } \\
\text { UUS }\end{array}$ & INF & $\begin{array}{c}\text { LOG } \\
\text { KURS }\end{array}$ & $\begin{array}{c}\text { BI_ } \\
\text { RATE }\end{array}$ \\
\hline Mean & 6.537107 & 7.256683 & 11.52493 & 11.21851 & 11.04209 & 9.361045 & 0.31239 & 9.55879 & 7.01075 \\
\hline Maximum & 9.706453 & 13.20004 & 13.26 & 13.27 & 12.94 & 12.06 & 2.46 & 9.70305 & 9.25 \\
\hline Minimum & 4.165941 & 4.345709 & 9.91 & 8.97 & 8.09 & 8.09 & -0.45 & 9.44501 & 5.79 \\
\hline Std. Dev. & 1.319047 & 2.344021 & 0.967437 & 1.180518 & 1.629137 & 0.84798 & 0.42993 & 0.04769 & 0.93187 \\
\hline Observations & 67 & 67 & 67 & 67 & 67 & 67 & 67 & 67 & 67 \\
\hline
\end{tabular}

Sumber: data diolah dengan eviews 9, 2020

\section{Uji Stasioneritas Data}

Pada penelitian ini uji stasioneritas data menggunakan uji akar unit yang telah dikembangkan oleh David Dickey dan Weyne Fuller dengan Augmanted DickleyFuller (ADF) Test. Apabila data time series tidak stasioner pada level atau ordo 1(0) maka data dapat diuji kembali ditingkat fisrt difference atau ordo 1(1) sehingga diperoleh data yang stasioner. Adapun hasil uji akar unit root dengan Augmented Dickey Fuller (ADF) dapat dilihat pada tabel 2 di bawah ini:

Tabel 2. Hasil Uji Stasioneritas (Augmented Dickey Fuller (ADF)

\begin{tabular}{|l|c|c|c|c|}
\hline \multirow{2}{*}{\multicolumn{1}{|c|}{ Variabel }} & \multicolumn{4}{c|}{ Tingkat Stasioneritas } \\
\cline { 2 - 5 } & Prob.Level & Keterangan & Prob.1st Difference & Keterangan \\
\hline PUMKMBUS & 0.0342 & Stasioner** & 0.0000 & stasioner* \\
\hline PUMKMUUS & 0.0765 & Stasioner*** & 0.0000 & stasioner* \\
\hline LOGJKBBUS & 0.2742 & Tidak Stasioner & 0.0000 & stasioner* \\
\hline LOGJKBUUS & 0.8473 & Tidak Stasioner & 0.0000 & stasioner* \\
\hline LOGDPKBUS & 0.9273 & Tidak Stasioner & 0.0000 & stasioner* \\
\hline LOGDPKUUS & 0.6441 & Tidak Stasioner & 0.0000 & stasioner* \\
\hline ROABUS & 0.4378 & Tidak Stasioner & 0.0000 & stasioner* \\
\hline
\end{tabular}




\begin{tabular}{|l|l|c|l|l|} 
ROAUUS & 0.0851 & Stasioner*** & 0.0000 & stasioner* \\
\hline NPFUMKMBUS & 0.5147 & Tidak Stasioner & 0.0000 & stasioner* \\
\hline NPFUMKMUUS & 0.7229 & Tidak Stasioner & 0.0000 & stasioner* \\
\hline ERPMUDHABUS & 0.7740 & Tidak Stasioner & 0.0000 & stasioner* \\
\hline ERPMUDHAUUS & 0.9851 & Tidak Stasioner & 0.0000 & stasioner* \\
\hline ERPMUSYBUS & 0.7441 & Tidak Stasioner & 0.0000 & stasioner* \\
\hline ERPMUSYUUS & 0.9285 & Tidak Stasioner & 0.0015 & stasioner* \\
\hline INF & 0.0000 & Stasioner* & 0.0000 & stasioner* \\
\hline LOGKURS & 0.6770 & Tidak Stasioner & 0.0000 & stasioner* \\
\hline BI_RATE & 0.4250 & Tidak Stasioner & 0.0003 & stasioner* \\
\hline
\end{tabular}

Keterangan: Nilai Critis MacKinnon $* \propto=1 \%, * * \propto=5 \%, * * * \propto=10 \%$

Sumber: Data diolah dengan Eviews 9, 2020

Berdasarkan Tabel 2 variabel PUMKMBUS, PUMKMUUS, ROAUUS, dan inflasi (INF) stasioner pada tingkat level dan variabel lainnya stasioner pada tingkat first difference. Hal tersebut menunjukkan bahwa kemungkinan regresi bersifat langsung dan data stasioner pada ordo yang berbeda. Oleh karena itu analisis pada penelitian ini dilakukan dengan menggunakan Autoregressive Distributed Lag (ARDL).

\section{Estimasi Model ARDL}

Penelitian ini menggunakan Akaike Information Criteria (AIC) untuk menentukan panjang kelambanan (lag). AIC menawarkan 20 model terbaik secara otomatis. Model terbaik dapat ditentukan dengan kriteria nilai terkecil dari 20 model terbaik yang ditawarkan oleh kriteria AIC. Berdasarkan gambar.1 Akaike Info Criterion (AIC), model ARDL terbaik untuk pembiayaan sector UMKM Bank Umum Syariah (PUMKMBUS) adalah ARDL (4, 4, 2, 4, 4, 3, 3, 3, 0, 4). Sedangkan berdasarkan Akaike Information Criterion (AIC), model ARDL terbaik untuk Prmbiayaan UMKM Unit Usaha Syariah (PUMKMUUS) adalah ARDL (4, 2, 0, $3,1,4,4,3,4,0)$.

\section{Uji Kointegrasi Bound Testing}

Hasil uji kointegrasi bound testing dapat dilihat pada tabel.3 di bawah ini:

Tabel 3. Hasil uji kointegrasi bound testing

\begin{tabular}{|c|c|c|c|c|}
\hline \multicolumn{5}{|c|}{ Pembiayaan Sektor UMKM BUS } \\
\hline Test Statistik & Value & Signifikansi & $\mathrm{I}(0)$ & $\mathrm{I}(1)$ \\
\hline F-statistic & 3.204221 & $10 \%$ & 1.88 & 2.99 \\
\hline $\mathrm{k}$ & 9 & $5 \%$ & 2.14 & 3.3 \\
\hline & & $2.50 \%$ & 2.37 & 3.6 \\
\hline & & $1 \%$ & 2.65 & 3.97 \\
\hline \multicolumn{5}{|c|}{ Pembiayaan Sektor UMKM UUS } \\
\hline Test Statistik & Value & Signifikansi & $\mathrm{I}(0)$ & $\mathrm{I}(1)$ \\
\hline F-statistic & 7.160399 & $10 \%$ & 1.88 & 2.99 \\
\hline \multirow[t]{3}{*}{$\mathrm{k}$} & 9 & $5 \%$ & 2.14 & 3.3 \\
\hline & & $2.50 \%$ & 2.37 & 3.6 \\
\hline & & $1 \%$ & 2.65 & 3.97 \\
\hline
\end{tabular}

Keterangan: Nilai Critis MacKinnon $* \propto=1 \%, * * \propto=5 \%, * * * \propto=10 \%$

Sumber: Data diolah dengan Eviews, 2020

Menurut hasil dari hasil uji kointegrasi pada table. 3 di atas dapat diketahui bahwa nilai FStatistik pada persamaan pembiayaan sektor UMKM Bank Umum Syariah (BUS) sebesar 3.204221 lebih besar dari nilai batas atas I(0) dan I(1) dengan tingkat signifikansi $10 \%$. Hal tersebut menunjukkan bahwa terdapat hubungan jangka panjang antara ketujuh variabel 
determinan terhadap pembiayaan sektor UMKM Bank Umum Syariah (BUS). Kemudian dapat diketahui bahwa nilai F-Statistik pada persamaan persamaan pembiayaan sektor UMKM Unit Usaha Syariah (UUS) sebesar 7.160399 lebih besar dari nilai batas atas I(0) dan I(1) dengan tingkat signifikansi 1\%. Maka dapat diketahui bahwa terdapat hubungan jangka panjang antara ketujuh variabel determinan terhadap persamaan pembiayaan sektor UMKM Unit Usaha Syariah (UUS).

5. Estimasi ECM Berbasis ARDL

a. Hasil Estimasi Pembiayaan Sektor UMKM Unit Usaha Syariah (UUS) model Error Corection Model (ECM) berbasis ARDL sebagai berikut:

Tabel 4 . Hasil Estimasi ECM Pembiayaan Sektor UMKM Bank Umum Syariah (BUS) Model ECM Berbasis ARDL

Dependent Variable: PUMKMBUS

Selected Model: ARDL(4, 4, 2, 4, 4, 3, 3, 3, 0, 4)

\begin{tabular}{|c|c|c|c|c|}
\hline \multicolumn{5}{|c|}{ Cointegrating Form } \\
\hline Variable & Coefficient & Std. Error & t-Statistic & Prob. \\
\hline D(PUMKMBUS(-1)) & 0.420293 & 0.226224 & 1.857862 & 0.0766 \\
\hline D(PUMKMBUS(-2)) & 0.355714 & 0.205860 & 1.727946 & 0.0980 \\
\hline D(PUMKMBUS(-3)) & 1.001231 & 0.247214 & 4.050066 & 0.0005 \\
\hline D(LOGJKBBUS) & -9.222817 & 12.637499 & -0.729798 & 0.4732 \\
\hline D(LOGJKBBUS(-1)) & -10.319226 & 9.414323 & -1.096120 & 0.2849 \\
\hline D(LOGJKBBUS(-2)) & -7.612342 & 9.919539 & -0.767409 & 0.4510 \\
\hline D(LOGJKBBUS(-3)) & -9.220422 & 9.062588 & -1.017416 & 0.3200 \\
\hline D(LOGDPKBUS) & -18.129305 & 13.389112 & -1.354033 & 0.1895 \\
\hline D(LOGDPKBUS(-1)) & -17.418462 & 11.611732 & -1.500074 & 0.1478 \\
\hline $\mathrm{D}(\mathrm{ROABUS})$ & -4.835099 & 1.549789 & -3.119843 & 0.0050 \\
\hline D(ROABUS(-1)) & 2.330743 & 1.497527 & 1.556395 & 0.1339 \\
\hline $\mathrm{D}(\mathrm{ROABUS}(-2))$ & -3.323774 & 1.558822 & -2.132235 & 0.0444 \\
\hline D(ROABUS(-3)) & 2.300634 & 1.413077 & 1.628102 & 0.1177 \\
\hline D(NPFUMKMBUS) & 0.501286 & 0.470491 & 1.065453 & 0.2982 \\
\hline D(NPFUMKMBUS(-1)) & -0.838692 & 0.408649 & -2.052352 & 0.0522 \\
\hline D(NPFUMKMBUS(-2)) & 0.590845 & 0.445490 & 1.326283 & 0.1984 \\
\hline D(NPFUMKMBUS(-3)) & -0.408211 & 0.460776 & -0.885921 & 0.3852 \\
\hline D(ERPMUDHABUS) & -2.134609 & 1.307718 & -1.632315 & 0.1168 \\
\hline D(ERPMUDHABUS(-1)) & 1.015697 & 1.023314 & 0.992557 & 0.3317 \\
\hline D(ERPMUDHABUS(-2)) & -1.884707 & 0.976178 & -1.930701 & 0.0665 \\
\hline D(ERPMUSYBUS) & -0.452676 & 0.559164 & -0.809558 & 0.4269 \\
\hline D(ERPMUSYBUS(-1)) & 1.567833 & 0.731098 & 2.144491 & 0.0433 \\
\hline D(ERPMUSYBUS(-2)) & -0.910698 & 0.633376 & -1.437846 & 0.1646 \\
\hline $\mathrm{D}(\mathrm{INF})$ & -0.911627 & 0.884568 & -1.030590 & 0.3139 \\
\hline $\mathrm{D}(\mathrm{INF}(-1))$ & -1.081282 & 0.622257 & -1.737677 & 0.0962 \\
\hline $\mathrm{D}(\mathrm{INF}(-2))$ & 1.183367 & 0.536518 & 2.205642 & 0.0382 \\
\hline D(LOGKURS) & -15.620474 & 9.991194 & -1.563424 & 0.1322 \\
\hline D(BI_RATE) & -5.764690 & 2.546592 & -2.263688 & 0.0338 \\
\hline D(BI_RATE(-1)) & 20.240335 & 5.727680 & 3.533776 & 0.0019 \\
\hline D(BI_RATE(-2)) & 0.780579 & 4.743778 & 0.164548 & 0.8708 \\
\hline D(BI_RATE(-3)) & -4.977707 & 2.855463 & -1.743222 & 0.0953 \\
\hline CointEq(-1) & -0.562440 & 0.184905 & -3.041778 & 0.0060 \\
\hline
\end{tabular}

Cointeq $=$ PUMKMBUS $-(72.4660 *$ LOGJKBBUS + 11.7514*LOGDPKBUS

$-3.3754 *$ ROABUS $+1.8505 *$ NPFUMKMBUS $+2.2414 *$ ERPMUDHABUS

$-2.4989 *$ ERPMUSYBUS $-6.6357 *$ INF $-27.7727 *$ LOGKURS -1.1559

*BI_RATE -396.7308)

Long Run Coefficients

\begin{tabular}{lllll}
\hline \hline Variable & Coefficient & Std. Error & t-Statistic & Prob. \\
\hline \hline
\end{tabular}




\begin{tabular}{crrrl} 
LOGJKBBUS & 72.465958 & 24.251808 & 2.988064 & 0.0068 \\
LOGDPKBUS & 11.751372 & 19.206326 & 0.611849 & 0.5469 \\
ROABUS & -3.375418 & 3.279822 & -1.029147 & 0.3146 \\
NPFBUS & 1.850494 & 1.572489 & 1.176793 & 0.2519 \\
ERPMUDHABUS & 2.241443 & 1.480946 & 1.513522 & 0.1444 \\
ERPMUSYBUS & -2.498941 & 1.891206 & -1.321348 & 0.2000 \\
INF & -6.635724 & 3.601654 & -1.842410 & 0.0789 \\
LOGKURS & -27.772712 & 19.818634 & -1.401343 & 0.1751 \\
BI_RATE & -1.155892 & 2.633570 & -0.438907 & 0.6650 \\
C & -396.730763 & 342.750335 & -1.157492 & 0.2595 \\
\hline \hline
\end{tabular}

Sumber:Data diolah dengan Eviews, 2020

Hasil estimasi pembiayaan sektor UMKM BUS melalui pendekatan ARDL yang ditampilkan pada Tabel 4 di atas memperlihatkan bahwa memang terdapat hubungan kointegrasi antara variabel pembiayaan sektor UMKM BUS dengan variabel karakteristik bank dan faktor makroekonomi. Hal ini terlihat dari koefisien ECT/CointEq yang berkoefisien negatif dan signifikan yakni -0.562440 dengan nilai probabilitas 0.0060 atau signifikan pada $\propto=1 \%$. Keadaan tersebut memberikan gambaran bahwa variabel-variabel independen cukup besar mempengaruhi variabel dependenya. Nilai koefesien tersebut menunjukan bahwa model akan menuju pada keseimbangan dengan kecepatan $56 \%$ perbulan. Selanjutnya hasil estimasi jangka panjang terlihat bahwa variabel JKB mempunyai pengaruh positif dan signifikan. Hal ini memperlihatkan bahwa perluasan jaringan kantor bank perlu jadi perhatian agar lembaga keuangan (bank) dapat diakses oleh masyarakat secara luas, yang mana nantinya akan berdampak terhadap pehimpunan dan penyaluran dana bank. Variabel inflasi dalam jangka panjang berpengaruh negatif dan signifikan hal ini menunjukkan bahwa ketika inflasi mengalami kenaikan maka harus akan menurunkan proporsi pembiayaan sektor UMKM. Apabila kenaikan inflasi tidak dibenahi maka pembiyaan sektor UMKM akan terus mengalami penurunan.

b. Hasil Estimasi Pembiayaan Sektor UMKM Unit Usaha Syariah (UUS) model Error Corection Model (ECM) berbasis ARDL sebagai berikut:

Tabel 5 . Hasil Estimasi Pembiayaan Sektor UMKM Unit Usaha Syariah (UUS) Model ECM Berbasis ARDL

Dependent Variable: PUMKMUUS

Selected Model: ARDL(4, 2, 0, 3, 1, 4, 4, 3, 4, 0)

\begin{tabular}{|c|c|c|c|c|}
\hline \multicolumn{5}{|c|}{ Cointegrating Form } \\
\hline Variable & Coefficient & Std. Error & t-Statistic & Prob. \\
\hline D(PUMKMUUS(-1)) & 0.055081 & 0.214209 & 0.257139 & 0.7990 \\
\hline D(PUMKMUUS(-2)) & 0.402423 & 0.159578 & 2.521790 & 0.0176 \\
\hline D(PUMKMUUS(-3)) & 0.165100 & 0.136111 & 1.212981 & 0.2353 \\
\hline D(LOGJKBUUS) & -12.081628 & 6.775295 & -1.783189 & 0.0854 \\
\hline D(LOGJKBUUS(-1)) & 14.864666 & 6.781729 & 2.191870 & 0.0369 \\
\hline D(LOGDPKUUS) & 3.375378 & 2.653773 & 1.271917 & 0.2139 \\
\hline D(ROAUUS) & -2.360635 & 0.786359 & -3.001980 & 0.0056 \\
\hline D(ROAUUS(-1)) & -1.566542 & 0.957603 & -1.635899 & 0.1131 \\
\hline D(ROAUUS(-2)) & -1.390112 & 0.920630 & -1.509958 & 0.1423 \\
\hline D(NPFUUS) & 0.025765 & 0.141251 & 0.182406 & 0.8566 \\
\hline D(ERPMUDHAUUS) & 0.142242 & 0.573758 & 0.247913 & 0.8060 \\
\hline D(ERPMUDHAUUS(-1)) & 1.340366 & 0.744191 & 1.801104 & 0.0825 \\
\hline D(ERPMUDHAUUS(-2)) & -2.056983 & 0.753020 & -2.731643 & 0.0108 \\
\hline D(ERPMUDHAUUS(-3)) & 1.230379 & 0.626352 & 1.964356 & 0.0595 \\
\hline D(ERPMUSYUUS) & 0.785145 & 0.570908 & 1.375256 & 0.1800 \\
\hline D(ERPMUSYUUS(-1)) & 1.125494 & 0.452516 & 2.487194 & 0.0191 \\
\hline D(ERPMUSYUUS(-2)) & 0.668682 & 0.455726 & 1.467287 & 0.1534 \\
\hline D(ERPMUSYUUS(-3)) & -2.121718 & 0.423230 & -5.013154 & 0.0000 \\
\hline $\mathrm{D}(\mathrm{INF})$ & 0.839304 & 0.678396 & 1.237188 & 0.2263 \\
\hline
\end{tabular}




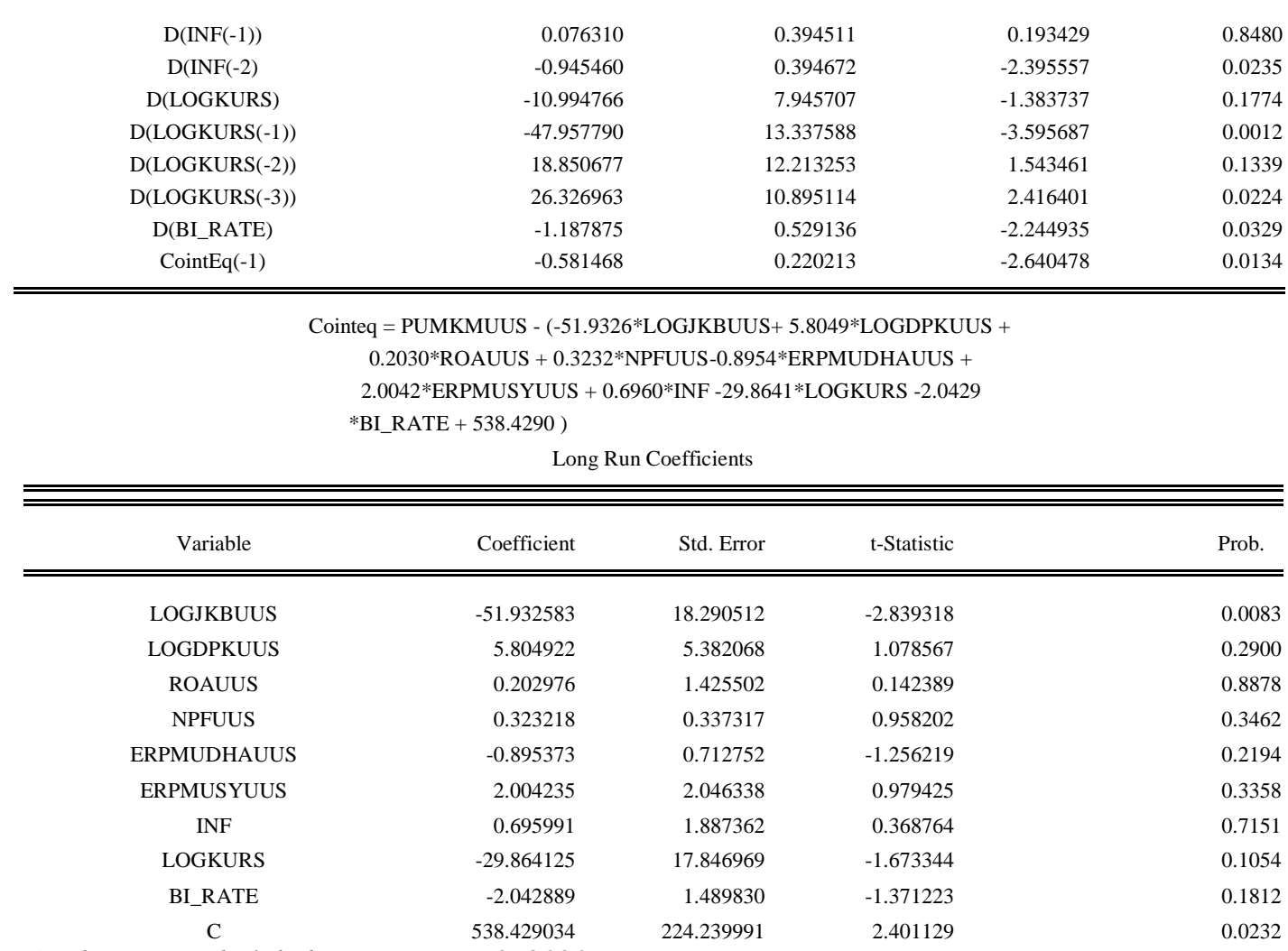

Sumber: Data diolah dengan Eviews 9, 2020

Hasil estimasi pembiayaan sektor UMKM UUS model ECM berbasis ARDL yang ditampilkan pada Tabel.5 di atas memperlihatkan bahwa memang terdapat hubungan kointegrasi antara variabel pembiayaan sektor UMKM UUS dengan variabel karakteristik bank dan faktor makroekonomi. Hal ini terlihat dari koefisien ECT/CointEq yang berkoefisien negatif sebesar -0.581468 dan signifikan yakni dengan nilai probabilitas 0.0134 atau signifikan pada $\propto=5 \%$. Keadaan tersebut memberikan gambaran bahwa variabel-variabel independen cukup besar mempengaruhi variabel dependenya. Nilai koefesien tersebut menunjukan bahwa model akan menuju pada keseimbangan dengan kecepatan $58 \%$ perbulan. Selanjutnya hasil estimasi jangka panjang terlihat bahwa variabel JKB mempunyai pengaruh negatif dan signifikan. Artinya apabila terjadi peningkatan jumlah jaringan kantor bank dapat mengurangi proporsi pembiayaan sektor UMKM karena untuk memahami perbankan syariah membutuhkan waktu dan kegiatan promosi ke masyarakat terus diupayakan agar tujuan pendirian perbankan dapat tercapai.

\section{Pengaruh Jaringan Kantor Bank (JKB) terhadap Pembiayaan Sektor UMKM BUS, Pembiayaan Sektor UMKM UUS}

Estimasi ECM berbasis ARDL dari kedua persamaan tersebut menunjukkan hasil yang berbeda-beda. variabel JKB dalam jangka pendek mempunyai koefisien negatif dan tidak signifikan sementara dalam jangka panjang variabel JKB memiliki koefisien positif dan signifikan pada pembiayaan sektor UMKM BUS. Variabel JKB dalam jangka pendek maupun jangka panjang mempunyai koefisisen negatif namun signifikan pada pembiayaan sektor UMKM UUS. Hasil penelitian ini sesuai dengan hipotesis bahwa JKB berpengaruh positif terhadap pembiayaan sektor UMKM BUS, pembiayaan sektor UMKM UUS. JKB berkaitan dengan kemudahan fasilitas serta pelayanan yang ditawarkan pada masyarakat atau kemudahan masyarakat dalam mengakses lembaga keuangan. Mengingat bahwa UMKM tersebar diseluruh kota, daerah serta pelosok-pelosok daerah jika kantor bank dapat menyebar keseluruh kota, daerah dan tempat-tempat pelosok maka secara tidak langsung akan 
meningkatkan pembiayaan sektor UMKM. Dapat dikatakan pula bahwa banyaknya jumlah kantor bank akan mempengaruhi jumlah DPK banyaknya jumlah DPK akan menambah proporsi jumlah pembiayaan yang disalurkan ke sektor UMKM.

\section{Pengaruh Dana Pihk Ketika (DPK) terhadap Pembiayaan Sektor UMKM BUS, Pembiayaan Sektor UMKM UUS}

Estimasi ECM berbasis ARDL dari kedua persamaan tersebut menunjukkan pengaruh yang berbeda-beda. variabel DPKBUS dalam jangka pendek berkoefisien negatif dan tidak signifikan pembiayaan sektor UMKM BUS sementara dalam jangka panjang variabel DPK memiliki koefisien positif, namun tidak signifikan. Kemudian pada pembiayaan sektor UMKM UUS variabel DPK dalam jangka pendek maupun jangka panjang berkoefisien positif namun tidak signifikan Penelitian ini menolak hipotesis yang menyatakan bahwa DPK berpengaruh positif terhadap pembiayaan sektor UMKM BUS, pembiayaan sektor UMKM UUS. Dimana dapat dijelaskan bahwa kenaikan DPK secara langsung meningkatkan total pembiayaan, namun tidak diikuti dengan peningkatan jumlah pembiayaan pada sektor UMKM BUS, pembiayaan pada sektor UMKM UUS. Hal tersebut terjadi disebabkan oleh keputusan internal perbankan syariah (BUS, dan UUS) yang mengalokasikan dana DPK tersebut kepada sektor-sektor lainnya seperti sektor rumah tangga yang lebih menguntungkan. Selain itu tuntutan bagi bank untuk memberikan tingkat bagi hasil atau marjin yang kompetitif kepada para nasabah penabung, agar tetap menabung diperbankan syariah, membuat atau mendorong para pihak perbankan syariah untuk menyalurkan dana yang dihimpun ke sektorsektor yang memberikan bagi hasil atau margin yang cepat seperti pada intrumen keuangan yakni SWBI, SBIS, PUAS dan lain sebagainya. Hasil penelitian ini menunjukkan bahwa perbankan syariah baik itu BUS, UUS belum memprioritaskan sektor produktif dalam penayluran DPK.

Selain itu penelitian ini juga sejalan dengan penelitian yang dilakukan oleh Irawan, dkk dengan objek penelitian pembiayaan UMKM di Bank Muamalat, Bank Syariah Mandiri dan Bank Syariah Mega yang menyatakan bahwa DPK mempunyai pengaruh signifikan terhadap pembiayaan UMKM. DPK merupakan sumber dana terbesar yang digunakan bank dalam penyaluran pembiayaan kepada masyarakat. Selain disalurkan ke sektor-sektor yang dapa memberikan bagi hasil atau margin yang cepat seperti pada instrument keuangan yakni SWBI, SBIS, dan PUAS, dan DPK yang telah dihimpun perbankan syariah disalurkan juga pada pembiayaan UMKM. DPK sangat memengaruhi kegiata perbankan, sebab jika DPK pada suatu bank meningkat maka dengan sendirinya bank tersebut akan menyalurkannya dana yang telah terhimpun tersebut kepada pembiayaan. Jika Hal tersebut tidak dilakukan maka bank justru akan mengalami kerugian seperti kerugian menanggung biaya operasional pemilik dana dan kerugian berkurangnya pendapatan.

\section{Pengaruh Return On Asset (ROA) terhadap Pembiayaan Sektor UMKM BUS, Pembiayaan Sektor UMKM UUS}

Estimasi ECM berbasis ARDL dari kedua persamaan tersebut menunjukkan hasil yang berbeda-beda. Pada pembiayaan sektor UMKM BUS, menunjukkan bahwa variabel ROA dalam jangka pendek maupun jangka panjang berkoefisien negatif dan signifikan. Pada pembiayaan sektor UMKM UUS, menunjukkan bahwa variabel ROA dalam jangka pendek berkoefisien negatif dan signifikan dan variabel ROA dalam jangka panjang memiliki koefisien positif dan tidak signifikan.

Menurut teori ROA berpengaruh positif terhadap pembiayaan UMKM, namun hasil penelitian ini berbeda dimana ROA berpengaruh negatif terhadap pembiayaan UMKM. 
Penelitian ini menolak hipotesis yang menyatakan bahwa ROA berpengaruh positif terhadap pembiayaan sektor UMKM BUS, pembiayaan sektor UMKM UUS. Dapat dijelaskan bahwa ROA menggambarkan seberapa banyak perusahaan telah memperoleh hasil atas sumber daya keuangan yang yang ditanamkan oleh perusahaan (perbankan). Diduga bahwa sumber keuangan bank yang ditanamkan atau disalurkan tidak menghasilkan laba yang cukup optimal hal ini dapat lihat dari pembiayaan yang masih mempunyai nilai NPF yang masih cukup tinngi. Adapun data terakhir yang tercatat pada April 2020 menunjukkan bahwa nilai NPFUMKMBUS sebesar 4,59\%, dan nilai NPFUMKMUUS sebesar 12,59\% masih tingginya tingkat NPF ini mempengaruhi profit perbankan tersebut. Jika nilai laba menurun menyebabkan jumlah pembiayaan yang disalurkan juga ikut menurun. Penelitian ini sejalan dengan penelitian yang dilakukan oleh Agista tentang pengaruh DPK, CAR, ROA, dan NPF terhadap pembiayaan bank syariah bahwa ROA mempunyai pengaruh negatif dan signifikan terhadap pembiayaan di PT Bank Muamalat Indonesia TBK.

Perbedaan hasil penelitian ini dengan hipotesis diduga juga disebabkan karena data ROA yang digunakan dalam penelitian ini merupakan data dari semua kegiatan yang dilakukan dalam satu tahun dan bukan data ROA yang khusus dihasilkan dari kegiatan perbankan syariah dalam melayani UMKM. Selain itu juga periode data dalam penelitian ini masih kurang panjang sehingga menghasilkan estimasi yang kurang optimal. Penelitian ini mendukung penelitian Irawan (2016) dengan objek penelitian pembiayaan UMKM di BMI, BMS, dan BSM, menyatakan bahwa ROA mempunyai pengaruh positif terhadap pembiayaan UMKM. ROA yang menggambarkan kemmampuan bank dalam mengelolah sumber daya keuangan meningkat maka dana yang disalurkan pada pembiayaan UMKM juga meningkat.

\section{Pengaruh Non Performing Financing (NPF) terhadap Pembiayaan Sektor UMKM BUS, Pembiayaan Sektor UMKM UUS}

Estimasi ECM berbasis ARDL dari kedua persamaan tersebut menunjukkan hasil yang berbeda-beda. Variabel NPF tidak mempunyai pengaruh signifikan terhadap pembiayaan sektor UMKM BUS dan pembiayaan sektor UMKM UUS. Hasil penelitian ini menolak hipotesis yang menyatakan NPF mempunyai pengaruh positif terhadap pembiayaan sektor UMKM BUS, pembiayaan sektor UMKM UUS. NPF merupakan resiko tidak terbayarnya pembiayaan yang disalurkan oleh bank. Adapun nilai NPF yang tinggi mengakibatkan bank kesulitan dalam mengelola kembali dananya, persediaan dana menjadi berkurang, pembiayaaan menjadi berkurang, maka dari itu pihak bank akan lebih berhati-hati dalam menyalurkan dananya kepada masyarakat. NPF merupakan pembiayaan bermasalah sehingga semakin tinggi masalah pembiayaan, maka akan mengurangi jumlah pembiayaan itu sendiri. Alasannya adalah ketika ada pembiayaan bermasalah, dana perbankan syariah tidak dapat dialihkan dari satu nasabah ke nasabah lain. Pembiayaan bermasalah yang lebih tinggi menyebabkan bank harus menyiapkan dana penghapusan yang lebih besar yang dapat menurunkan minat bank untuk mendistribusikan dana melalui pembiayaan.

\section{Pengaruh Equivalent Rate Pembiayaan (ERP) terhadap Pembiayaan Sektor UMKM BUS, Pembiayaan Sektor UMKM UUS}

Estimasi ECM berbasis ARDL kedua persamaan tersebut menunjukkan hasil yang berbeda-beda. Variabel equivalent rate pembiayaan (ERPMUDHA) dalam jangka pendek berpengaruh negatif dan tidak signifikan sementara dalam jangka panjang variabel equivalent rate pembiayaan (ERPMUDHA) berpengaruh positif dan tidak signifikan terhadap pembiayaan sektor UMKM BUS. Variabel equivalent rate pembiayaan (ERPMUSY) dalam jangka pendek maupun jangka panjang tidak berpengaruh terhadap pembiayaan sektor 
UMKM BUS. Variabel equivalent rate pembiayaan (ERPMUDHA) dalam jangka pendek maupun jangka panjang berpengaruh positif dan tidak signifikan terhadap pembiayaan sektor UMKM UUS. Variabel equivalent rate pembiayaan (ERPMUSY) dalam jangka pendek maupun jangka panjang berpengaruh positif dan tidak signifikan terhadap pembiayaan sektor UMKM UUS. Variabel ERPMUDHA dan MUSYA tidak berpengaruh signifikan terhadap pembiayaan sektor UMKM BUS dan pembiayaan sektor UMKM UUS. Hasil penelitian ini menolak hipotesis yang menyatakan bahwa ERP mempunyai pengaruh yang positif dan signifikan terhadap pembiayaan sektor UMKM BUS dan pembiayaan sektor UMKM UUS. Pembiayaan sektor UMKM merupakan pembiayaan yang mempunyai risiko cukup tinggi karena bagi hasil yang didapat bergantung pada hasil usaha yang dijalankan sehingga perbankan syariah juga cenderung menerapkan ERP yang tinggi pula. ERP yang tinggi akan meningkatkan pendapatan bank dan meningkatkan proporsi pembiayaan. Namun ERP yang meningkat akan mengakibatkan kecilnya pendapatan yang diperoleh nasabah sehingga nasabah akan mencari alternatif pembiayaan lain ke kredit bank konvensional misalnya sehingga pembiayaan UMKM menurun. Karena pada bank konvensional menjanjikan pengembalian yang lebih tinggi dengan risiko yang rendah dari pada memberikan pembiayaan ke UMKM yang meminta pengembalian yang tinggi dan lebih berisiko. Hal ini akan mengurangi distribusi dana bank pada pembiayaan UMKM. Namun penelitian ini mendukung hipotesis yang menyatakan bahwa ERP berpengaruh positif dan signifikan terhadap pembiayaan UMKM seperti penelitian Yuningsih dengan objek penelitian pembiayaan sektor jasa dunia usaha pada perbankan syariah yang menyatakan bahwa ERP berpengaruh terhadap pembiayaan perbankan syariah ERP yang tinggi akan meningkatkan proporsi pembiayaan bank karena pendapatan bank juga meningkat.

\section{Pengaruh Inflasi terhadap Pembiayaan Sektor UMKM BUS, Pembiayaan Sektor UMKM UUS.}

Estimasi ECM berbasis ARDL kedua persamaan tersebut menunjukkan hasil yang berbeda-beda. variabel inflasi dalam jangka pendek berpengaruh negatif dan tidak signifikan sementara dalam jangka panjang variabel inflasi berpengaruh negatif dan signifikan terhadap pembiayaan sektor UMKM BUS. Variabel inflasi dalam jangka pendek berpengaruh negatif dan tidak signifikan sementara dalam jangka panjang variabel inflasi berpengaruh positif tidak signifikan terhadap pembiayaan sektor UMKM UUS. Inflasi tidak berpengaruh signifikan terhadap pembiayaan sektor UMKM BUS dalam jangka pendek, dan dalam jangka panjang berpengaruh signifikan. Secara teori tingkat inflasi yang tinggi akan mempengaruhi kenaikan harga-harga barang yang akan berdampak pada daya beli masyarakat yang menurun. Namun hasil penelitian ini tidak menggambarkan hal tersebut. Inflasi tidak signifikan mempengaruhi pembiayaan UMKM karena walaupun tingkat inflasi dalam keadaan fluktuatif masyarakat tetap membutuhkan modal untuk menambah dana agar tetap berproduksi dalam menjalankan usahanya. Modal tersebut dapat diperoleh dari pembiayaan dari perbankan. Jumlah pembiayaan yang dikeluarkan akan meningkat karena harga-harga yang meningkat. Hal tersebut yang mengambarkan bahwa inflasi berpengaruh signifikan terhadap pembiayaan sektor UMKM BUS.

\section{Pengaruh Nilai Tukar terhadap Pembiayaan Sektor UMKM BUS, Pembiayaan Sektor UMKM UUS.}

Estimasi ECM berbasis ARDL kedua persamaan tersebut menunjukkan hasil yang sama.Variabel nilai tukar dalam jangka pendek maupun jangka panjang berpengaruh negatif dan tidak signifikan terhadap pembiayaan sektor UMKM BUS. Variabel nilai tukar dalam 
jangka pendek maupun jangka panjang berpengaruh negatif dan tidak signifikan terhadap pembiayaan sektor UMKM UUS. Variabel nilai tukar dalam jangka pendek maupun jangka panjang berpengaruh negatif dan tidak signifikan terhadap pembiayaan sektor UMKM BPRS. Dapat disimpulkan bahwa variabel nilai tukar dalam jangka pendek maupun jangka panjang tidak signifikan mempengaruhi pembiayaan sektor UMKM BUS, pembiayaan sektor UMKM UUS. Hal tersebut dapat terjadi karena perbankan syariah fokus tujuannya adalah menyalurkan pembiayaannya pada sektor riil seperti pembiayaan sektor UMKM. Pangsa pasar UMKM masih didominasi pada pasar domestik. Sehingga apabila terjadi fluktuasi nilai tukar tidak mempengaruhi nilai pembiayaan pada sektor UMKM. Sehingga penelitian ini menolak hipotesis yang menyatakan bahwa nilai tukar berpengaruh negatif signifikan terhadap pembiayaan sektor UMKM BUS, dan pembiayaan sektor UMKM UUS. Penelitian ini sejalan dengan penelitian Bambang \& Sudrajat (2016) dengan objek penelitian pembiayaan UMKM bank umum syariah di Jambi yang menyatakan bahwa nilai tukar berpengaruh negatif dan tidak signifikan terhadap pembiayaan UMKM.

\section{Pengaruh Tingkat Suku Bunga (BI-Rate) terhadap Pembiayaan Sektor UMKM BUS, Pembiayaan Sektor UMKM UUS.}

Estimasi ECM berbasis ARDL dari kedua persamaan tersebut menunjukkan hasil yang berbeda. Variabel tingkat suku bunga dalam jangka pendek berpengaruh negatif dan signifikan sementara dalam jangka panjang variabel tingkat suku bunga berpengaruh negatif dan tidak signifikan terhadap pembiayaan sektor UMKM BUS. Variabel tingkat suku bunga dalam jangka pendek berpengaruh negatif dan signifikan sementara dalam jangka panjang variabel tingkat suku bunga berpengaruh negatif dan tidak signifikan terhadap pembiayaan sektor UMKM UUS. BI Rate adalah suku bunga kebijakan yang mencerminkan sikap atau stance kebijakan moneter yang ditetapkan oleh Bank Indonesia. Semakin rendah suku bunga Bank Indonesia maka semakin tinggi permintaan kredit pada bank konvensional. Hal ini berbanding terbalik dengan perbankan syariah yang tidak menggunakan suku bunga sebagai acuan pembiaayaan misalnya jika pembiayaan sektor UMKM menggunakan akad murabahah maka besaran angsuran yang dibayarkan kepada bank sudah ditetapkan di awal perjanjian sehingga dalam hal ini apabila terjadi fluktuasi suku bunga maka tidak mempengaruhi pembiayaan sektor UMKM. Hal ini juga yang menjadi salah satu alasan kenapa perbankan syariah dapat bertahan saat terjadi krisis. Penelitian ini sejalan dengan penelitian Wahiduddin (2018) dengan objek penelitian pembiayaan UKM bank umum syariah yang menyatakan bahwa tingkat suku bunga (BI_Rate) berpengaruh negatif tidak signifikan terhadap pembiayaan UKM.

\section{Kesimpulan}

Berdasarkan hasil penelitian maka dapat ditarik kesimpulan bahwa variabel yang berpengaruh terhadap pembiayaan sektor UMKM BUS dalam jangka pendek adalah return on assets (ROA) dan tingkat suku bunga (BI_Rate). Sedangkan dalam jangka panjang variabel yang berpengaruh terhadap pembiayaan sektor UMKM BUS adalah jaringan kantor bank (JKB), dan inflasi. Sementara variabel dana pihak ketiga (DPK), non performance financing (NPF), nilai tukar, equivalent rate pembiayaan (ERP) baik dalam jangka pendek maupun jangka panjang tidak berpengaruh terhadap pembiayaan sektor UMKM BUS. Kemudian variabel yang berpengaruh terhadap pembiayaan sektor UMKM UUS dalam jangka pendek adalah jaringan kantor bank (JKB), return on assets (ROA) dan tingkat suku bunga (BI_Rate). Sedangkan dalam jangka panjang variabel yang berpengaruh terhadap pembiayaan sektor 
UMKM UUS adalah jaringan kantor bank (JKB). Sementara variabel dana pihak ketiga (DPK), non performance financing (NPF), nilai tukar, equivalent rate pembiayaan (ERP) baik dalam jangka pendek maupun jangka panjang tidak berpengaruh terhadap pembiayaan sektor UMKM UUS.

Hasil penelitian ini memberikan gambaran serta rekomendasi kepada pihak perbankan dan pemerintah, yakni bagi pihak perbankan yakni bank umum syariah (BUS) maupun unit usaha syariah (UUS) perlu memperhatikan kembali kondisi karakteristiknya seperti perluasan jaringan kantor bank agar lembaga keuangan dapat di akses oleh masyarakat secara merata karena jaringan kantor ini mempunyai pengaruh yang signifikan terhadap pembiayaan dalam jangka panjang bagi BUS dan dalam jangka pendek maupun jangka panjang bagi UUS. Selanjutnya dapat memaksimalkan pendapatan dengan menginvestasikan dana yang dihimpun ke sektor-sektor produktif serta menaikan ERP secara wajar. Kemudian bagi pihak pemerintah diharapkan selalu mendukung kegiatan-kegiatan dalam upaya menciptakan pertumbuhan ekonomi Indonesia yang stabil mencakup inflasi, dan tingkat suku bunga (BIRate). Penelitian ini juga diharapkan dapat dijadikan sebagai referensi tambahan bagi peneliti selanjutnya untuk mengembangkan penelitian yang sejenis. Selain itu diharapkan juga penelitian selanjutnya dapat menggunakan data per level bank agar memperoleh hasil penelitian yang lebih tepat.

\section{Daftar Pustaka}

Ardiansyah, Hadira Thumaninah Jibril, David Kaluge, dan Kasnaeny Karim, 'Permintaan Pembiayaan Murabahah Berdasarkan Tingkat Inflasi Dan Suku Bunga BI Rate Pada Bank Syariah Di Indonesia', Jurnal Bisnis Dan Manajemen, 13.12019

Asnaini, ‘Analisis Pengembangan Umkm Berbasis Wakaf Uang Di Kota Bengkulu', Jurnal Baabu Al Ilmi, 3.12018

Astuti, Agnes Dwi., 'Pengaruh Jumlah Dana Pihak Ketiga (DPK), Inflasi, BI Rate dan Financing to Deosit Ratio (FDR) Terhadap Alokasi Pembiayaan UMKM Pada Bank Umum Syariah', 2017

Beik, Irfan Syauqi, dan Winda Nur Aprianti, 'Analisis Faktor-Faktor Yang Memengaruhi Pembiayaan Bank Syariah Untuk Sektor Pertanian Di Indonesia', Jurnal Agro Ekonomi, 31.12016

Dwijaya, Putra Agung dan Sugeng Wahyudi, 'Analisis Pengaruh Variabel Makro Ekonomi, Dengan Demografi Dan Efek Krisis Keuangan Global Sebagai Variabel Kontrol Terhadap Pembiayaan Bank Syariah Di Indonesia (Studi Pada Bank Syariah Devisa Di Indonesia Periode 2007-2016)', Diponegoro Journal of Management, 72018

Fitriani, Ningsih Devi, 'Analisis Faktor Yang Mempengaruhi Pembiayaan Mudharabah Pada Bank Umum Syariah Di Indonesia Periode 2013-2016', Jurnal Ilmiah Riset Akuntansi 6, 2017

Irawan, Oki, Khalil Jafril, dan Riawan Amin, 'Dana Pihak Ketiga, Rasio Kecukupan Modal, Pembiyaan Bermasalah, Dan Tingkat Pengembalian Investasi Pada Pembiayaan UMKM', Liquidity, 5.22018

Jaya, Yozar Putra Rindayati Wiwiek, dan Ali Khalifah Muhammad, , 'Analisis Faktor-Faktor Penentu Pembiayaan Perbankan Syariah Pada Sektor Pengangkutan Dan Komunikasi Di Indonesia', Al-Muzara'ah, 3.12016

Kurniawan, Bambang, dan Alpi M Sudrajat, 'Pengaruh PDRB Dan Nilai Tukar Terhadap Pembiayaan UMKM Pada Bank Umum Syariah Di Provinsi Jambi Periode 2010- 
2017', Jurnal IJIEB, 1.12017

Masudah, 'Determinan Volume Pembiayaan Bank Umum Syariah Indonesia', Ikonomika, 2.1 2017

Mustofa, Alic'Analisis Pengaruh Jumlah Kantor Bank Umum Syariah (JKBUS), Sertifikat Bank Indonesia Syariah (SBIS), dan Dana Pihak Ketiga (DPK) Terhadap Pembiayaan Bagi Hasil Pada Bank Umum Syariah di Indonesia Periode 2015 2018', April, 2019

Muzayyinulhaq, 'Analisis Permintaan Dan Penawaran Kredit Perbankan Di Indonesia', 2019

Nurochman, Rachmiawati Indah, 'Faktor Yang Mempengaruhi Pembiayaan Mudharabah Pada Bank Umum Syariah Di Indonesia’, Accounting Analysis Journal, 22019

Otoritas Jasa Keuangan, Statistik Perbankan Syariah April 2020, 2020

Pratiwi, Ririh Dian dan Prajanto Agung, 'Faktor Internal Dan Eksternal Sebagai Determinan Peningkatan Penyaluran Kredit Bank Umum Di Indonesia', 5.1 2020

Susilowati, Eko Meiningsih, and Endah Nawangsari, 'Pengaruh Kinerja Keuangan Terhadap Penyaluran Pembiayaan Pada Bank Umum Syariah di Indonesia : PERIODE 20132015 STIE Adi Unggul Bhirawa Surakarta', Jurnal Ekonomi Dan Perbankan, 3.1 2018

Trimulato, Ismawati, Amiruddin K, dan Nuraeni, 'Penguatan Peran Ekomomi Islam Melalui Optimalisasi Pembiayaan Pada Sektor Rill UMKM', Jurnal Ekonomi Syariah, 5.September 2020

Umiyati dan Leni Tantri Ana, 'Faktor-Faktor yang Mempengaruhi Pembiyaan Pada Bank Umum: Jurnal Ekonomi Dan Perbankan Syariah', November, 2018

Wahiddudin, Muhammad, 'Pengaruh Inflasi, Non Performing Finacing (Npf) dan Bi Rate Terhadap Pembiayaan Usaha Mikro Kecil dan Menengah (UMKM) Pada Bank Umum Syariah 2012-2017', Al Amwal, 1.12018

Warto, dan R Bambang Budhijana, 'Faktor - Faktor Yang Mempengaruhi Penyaluran Pembiayaan Perbankan Syariah Indonesia Periode 2009 - 2019', Al Maal: Journal of Islamic Economics and Banking, 1.12019

Yuningsih, Ayu, 'Analisis Pembiayaan Sektor Jasa Dunia Usaha Pada Perbankan Syariah Di Indonesia', Al-Intaj, 2020 